Yermagambet Bolat Toleukhanuly, Doctor of Chemistry, Professor, Director

E-mail: coaltech@bk.ru ORCID ID 0000-0003-1556-9526

Kazankapova Maira Kuttybayevna, PhD, Leading Researcher E-mail: maira_1986@mail.ru ORCID ID 0000-0001-9016-3062

Institute of Coal Chemistry and Technology

Nauryzbaeva Asemay Turlankyzy, Master's Degree student

Kazakh University of Technology and Business

Junior Researcher of LLP "Institute of Coal Chemistry and Technology"

E-mail: asemai_2296@mail.ru ORCID ID 0000-0003-4912-3856

Astana, the Republic of Kazakhstan

\title{
THE OBTAINING CARBON NANOFIBERS FROM A TEXTILE CORD BY ELECTROSPINNING METHOD
}

\begin{abstract}
The article work is devoted to obtaining carbon nanofibers from the textile cord by electrospinning method and studying the physicochemical properties of the obtained product.

Keywords: carbon nanofiber, electrospinning, textile cord, carbonization, stabilization.
\end{abstract}

Carbon nanofibers (CNFs) are a class of such materials in which curved graphene layers or nanocones are folded into a quasi-one-dimensional thread, whose internal structure can be characterized by the angle $\alpha$ between the graphene layers and the fiber axis [1]. CNF attracted a lot of attention of scientists for its potential thermal, electrical, shielding and mechanical properties [2]. Due to their exceptional properties and low cost, they are now increasingly used in various materials, such as composites.

The continuous growth of the car park in all developed countries leads to a constant increase in the number of worn tires. In accordance with the data of the European Tire Recycling Association (ETRA), more than 2.5 million tons of depreciated automobile tires are produced in Europe every year. At the same time, the total amount of their processing does not exceed $30 \%$. Worn tires are a source of long-term environmental pollution, as they are not biodegradable. Tires are also flammable and, in case of fire, it is quite difficult to extinguish them. At the same time, the depreciated automobile tires contain valuable raw materials: rubber, metal and textile cord.

Textile cord is a cord of fibers with rubber particles. It is obtained by recycling tires into rubber crumb. Automotive wheel consists of rubber, metal cord and textile material to give the wheel strength and durability. Textile cord is a polymeric compound that is actively used in industry, construction, production, etc. The composition of the textile cord: polyester - $60 \%$, polyamide - $37 \%$ (PA-6PA-66), viscose $-3.0 \%$, density - $0,1 \mathrm{~g} / \mathrm{cm} 3$. Usually, the cord is embedded inside at the stage of creating a material or a structural element. Most often used in the manufacture of rubber products: auto, air and other tires, rubber and plastic pipes and hoses, technical plates, etc. [3].

The purpose of this work is to obtain carbon nanofibers from textile cord, which are obtained from used automobile tires.

Experimental part. We have obtained carbon fiber from textile cord. Textile cord samples were provided by Kazakhstan Rubber Recycling LLP (Astana). To obtain the CNF, we have chosen the electrospinning method, since this method is acceptable under laboratory conditions, and fine fibers are formed. Electrospinning is good in that, unlike conventional mechanical pulling of fibers from a solution, it does not place high demands on the chemistry of the process, 
does not require high temperatures to harden the fiber, and therefore allows to create fibers from long and complex molecules as a result of the control of capillary and electrostatic forces. The method of electroforming allows to obtain polymer fibers with a diameter on the order of several hundred nanometers [4].This method has significant drawbacks. It does not allow working with solutions of polymers with a small dielectric constant. In addition, it uses high-voltage equipment, which, firstly, is quite expensive, and secondly, it makes serious demands on safety [5].

A typical electrospinning installation, as shown in Figure 1, consists mainly of three components: a capillary tube with a pipette or a small-diameter needle, a high voltage source, and a metal collecting screen.

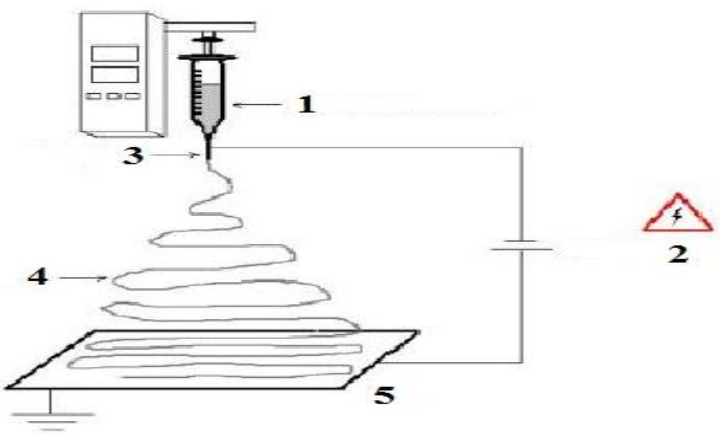

Figure 1 - Schematic diagram of the laboratory setup for the synthesis of CNF using the electrospinning method: 1-solution, 2-high power source, 3-capillary, 4-nanofibres, 5-substrate

At the first stage of preparation of the solution to obtain nanofibers, the process of carbonization of the cord was carried out at a temperature of $400^{\circ} \mathrm{C}$ in a laboratory quartz reactor. Heating and cooling of the quartz reactor was carried out in an inert atmosphere of argon. To obtain an CNF method using electrospinning, a textile cord is placed in a quartz reactor and heated to $4000^{\circ} \mathrm{C}$ at a heating rate of $10-15^{\circ} \mathrm{C} / \mathrm{min}$ and held at $400{ }^{\circ} \mathrm{C}$ for $3-4$ hours. Heating and cooling of the quartz reactor was carried out in an inert atmosphere of argon, at a gas velocity of $80 \mathrm{~cm} 3 / \mathrm{min}$. Then the reactor is cooled and the intermediate products are collected.

The resulting sample is crushed, 1,2-dichloroethane is added and placed in an ultrasonic bath for 10-20 minutes for complete mixing. Polymethyl methacrylate is used as a binder, which is also mixed with 1,2-dichloroethane in an ultrasonic bath for 30 minutes. The resulting mixture in ratios of $1: 1$ are placed in an ultrasonic bath for 40 minutes at a temperature of $35^{\circ} \mathrm{C}$. The finished mixture is collected in an insulin syringe and is installed on the reversing engine. A charge is applied to the tip of the syringe. Further, the engine turns on, and with the appearance of the first drop, the opposite charge is turned on. The charge of the same name is attracted to a substrate with an opposite charge and nanofibers are formed (Figure 3). Nanofibers are cured by solvent evaporation. The interelectrode voltage was $18-20 \mathrm{kV}$. High voltage is the basis of electroforming.

The process of electroforming begins when electrostatic forces between the charges accumulated in the molding solution and the electric field between the electrodes overcome the surface tension of the molding solution. The repulsive force between like charges stretches the visco-elastic stream of the molding solution.

The feed rate of the solution is 30 , the voltage is $20-30 \mathrm{kV}$, the distance is $30 \mathrm{~cm}$.

Carbon nanofibers from a textile cord
Materials of International Practical Internet Conference

"Challenges of Science" 


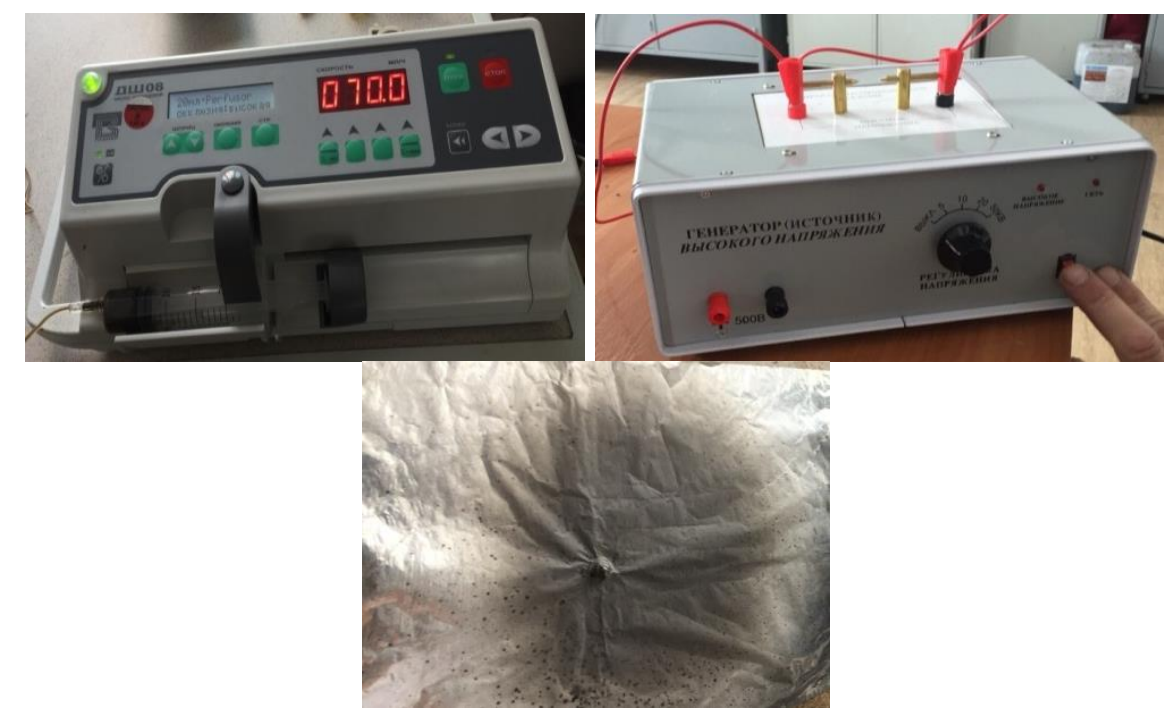

1)

2)

3)

Figure 2 - Laboratory installation of electrospinnagus: pump syringe (1), high-voltage power source (2), substrate of aluminum foil (3)

The study of the elemental composition, structure, and dimension of the CNF was performed by energy dispersive X-ray spectroscopy on a SEM instrument (Quanta 3D 200i) with an attachment for energy dispersive analysis from EDAX (NNLOT, Al-Farabi Kazakh National University, Almaty). For the study, the samples were fixed on a copper holder using conductive adhesive paper. The energy of the exciting electron beam in the analysis was 15 $\mathrm{keV}$, the working distance was $15 \mathrm{~mm}$.

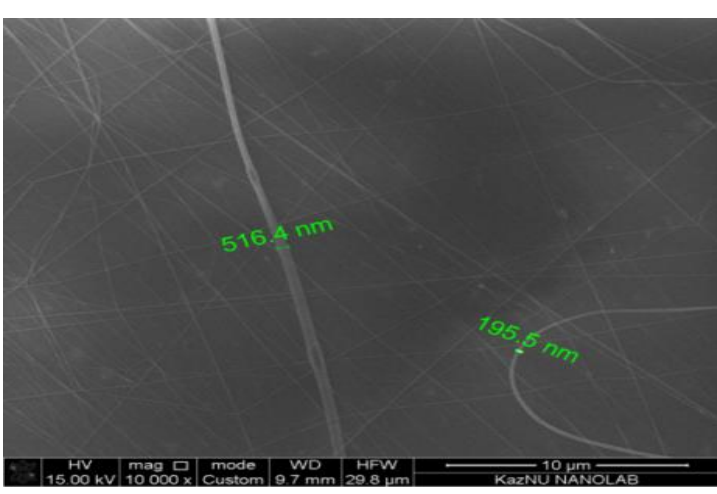

a)

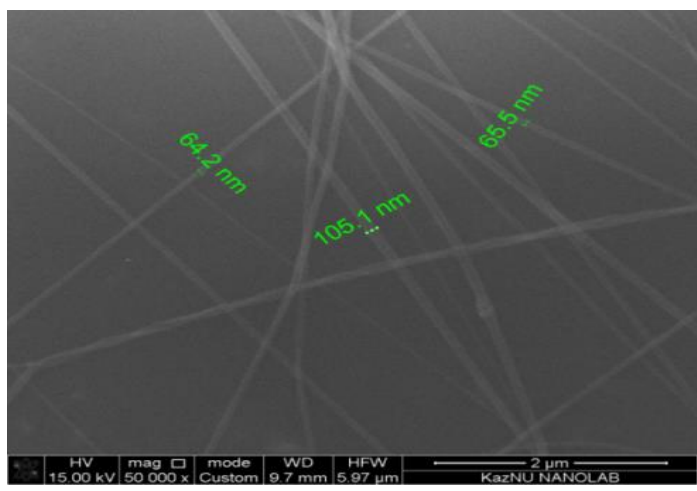

b)

Figure 3 - Electron microscopic images of the sample: a) x10 000 b) x50 000 on a scanning electron microscope

In Figure 4, particles of a CNF with a diameter of $64.2 \mathrm{~nm}$ to $516.4 \mathrm{~nm}$ are clearly visible, the structural elements take the form of fibrils - threadlike formations, whose lengths exceed the diameter by more than one core.

The elemental composition of carbon fibers was by wt.\%: C-82,69; O-1.72; Si-0.46.

Carbon nanofibers from a textile cord
Materials of International Practical Internet Conference

"Challenges of Science" 
On the first stage carbon nanofibres from textile cord by the method of electrospinning were obtained. The study is perspective due to its possibility of large-scale production of carbon fibers from textile cord on the market of Kazakhstan.

The present work was carried out within the framework of the scientific and technical program No. IRN BR05236359 on the topic: "Scientific and technological support of coal processing and production of high-conversion products of carbon chemistry" and by the project No. IRN AP05130707 on the topic: "Development of technology and creation of production of carbon nanocomposite materials based on mineral domestic raw materials for gas phase and wastewater purification" funded by the Science Committee of the Ministry of Education and Science of the Republic of Kazakhstan.

\section{LITERATURE}

1. A. V. Melechko, V. I. Merkulov, T. E. McKnight, M. A. Guillorn, K. L. Klein, D. H. Lowndes, and M. L. Simpson, J. Appl. Phys. 97, 041301 (2005)JAPIAU000097000004041301000001. | First Citation first citation in article.

2. Tibbetts, G.G., Lake, M.L., Strong, K.L., and Rice, B.P. "A Review of the Fabrication and Properties of Vapor-Grown Carbon Nanofiber/Polymer Composites, " Composites Science and Technology, 67(7-8) (2007):1709-1718.

3. Перепелкин К. Е. Армирующие волокна и волокнистые полимерные композиты, изд. 2009 (https://plastinfo.ru/information/articles/356)

4. Method of dispersing fluids. US Patent 705691 / Morton W.J., 1902. (https://patents.google.com/patent/US705691)

5. B.T. Ermagambet, M.K. Kazankapova, Zh.Kh.Ermogambetov, A.T. Nauryzbayeva, K.G. Kanagatov, L.D.Abylgazina. Methods for producing carbon Nanofibers from coal pitch, Reports Of the national academy of sciences Of the republic of Kazakhstan, 2018: 9-16. 